\title{
Comparison of the clinical parameters of benign prostate hyperplasia in diabetic and non diabetic patients
}

\author{
Levent Ozcan ${ }^{1}$, Huseyin Besiroglu ${ }^{2}$, Murat Dursun ${ }^{3}$, Emre Can Polat ${ }^{2}$, Alper Otunctemur ${ }^{2}$, Emin Ozbek ${ }^{2}$ \\ ${ }^{1}$ Department of Urology, Derince Training and Research Hospital, Kocaeli, Turkey; \\ 2 Department of Urology, Okmeydani Training and Research Hospital, Istanbul, Turkey; \\ ${ }^{3}$ Department of Urology, Bahcelievler State Hospital, Istanbul, Turkey.
}

\begin{abstract}
Summary Objective: We evaluated the correlation between benign prostate hyperplasia (BPH) measures and diabetes mellitus in men with benign prostate hyperplasia in a prospective study.

Materials and methods: Between 2008-2012, 100 diabetic and 200 non diabetic patients undergoing surgery due to benign prostate hyperplasia were enrolled in the study. The parameters evaluated for each patients included prostate volume, fasting blood glucose, HbAlc, total testosterone, total prostatic specific antigen (T-PSA), triglicerides, total cholesterol and body mass index (BMI). A questionnaire including international prostate symptom score (IPSS) was sdministered and uroflow test measuring the peak urinary flow rate was performed to appreciate the complaints of the patients objectively.

Results: Diabetic patients are more likely to have larger prostate volume. The symptom score evaluated by IPSS and post micturition residual volume were also significantly higher in diabetic groups. The other statistically significant different parameter between two groups was total testosterone that diabetic patients tend to have lower levels. Diabetic counterparts were established to have higher BMI. No statistically significant differentiation was observed about trigliceryde and total cholesterol levels and uroflow rates. Conclusions: Our study suggests a positive correlation between high prostate volume and diagnosis of diabetes mellitus in patients with benign prostatic hyperplasia. We also observed a positive correlation between symptom scores and post micturion residual volumes and diagnosis of diabetes mellitus suggesting that the presence of diabetes is related to both static and dynamic components of benign prostate hyperplasia. Additionally testosterone levels were lower in diabetic patients. Further studies need to confirm these relationship in a larger population.
\end{abstract}

KEY WORDS: Benign prostate hyperplasia; Diabetes; International prostate symptom score; Prostate volume; Prostatic Specific Antigen (PSA); Testosterone.

Submitted 23 May 2016; Accepted 3 September 2016

\section{INTRODUCTION}

Benign prostate hyperplasia (BPH) is a prevalent process in aging man with severe and frequent low urinary symptoms reducing the quality of life (1). Despite intense research to identify the underlying mechanism of prostatic growth in older man, cause and effect relationship has not been yet established $(2,3)$. The etiology of
$\mathrm{BPH}$ is still unclear, but multiple partially overlapping and complementary systems (nerve, endocrine, immune, and vascular) as well as local factors are likely to be involved $(2,4)$. Although the specific pathway remains poorly investigated, it seems that the pathogenetic mechanism is endocrine controlled (4). Diabetes Mellitus (DM) and BPH progression occur in similar ages in men and DM is thought to be an important entity contributing development and progression of $\mathrm{BPH}(5,7)$.

Histologically, BPH is a non malignant unregulated hyperplasia of stromal and epithelial prostate cells (8). It seems there is a significant correlation between prostate enlargement and DM. There are many reports suggesting a causal relationship between high insulin levels and the development of BPH and an increased sympathetic nerve activity in men with BPH has been suggested $(9,10)$. This process contributes to an increase in the activation of the alfa adrenergic system leading to smooth muscle contraction throughout genitourinary system particularily in the bladder neck and prostate $(11,12)$. Obesity is an another entity whose direct relationship was shown with BPH and lower urinary tract symptoms (LUTS) in many studies probably via secondary hyperinsulinemia or the increased estrogen-to-androgen ratio (13-19). Androgens are well known facts contributing to BPH/LUTS although they are not a clearly causative aspect of BPH. The relationship between sex hormones on regulation of prostatic growth and BPH/LUTS is quite complex and still not thoroughly understood (20, 21). Consequently, androgens, estrogens, stromal-epithelial interactions, growth factors and neurotransmitters may play a role, either singly or in combination, in the etiology of the hyperplastic process. The aim of this study to evaluate the BPH componenets in diabetic and non diabetic patients undergoing surgery owing to $\mathrm{BPH}$.

\section{Materials AND MethodS}

\section{Study population}

From 2008 to 2012300 patients undergoing surgery owing to BPH were included in the study. For patients with suspicious prostate cancer in terms of high prostate specific antigen (PSA) and abnormal digital rectal examination (DRE), ultrasonography guided transrectal biopsy 
was performed before surgery. The indications of TURP were provided as following: recurrent urinary retention, recurrent urinary tract infections, recurrent macroscopic hematuria, bladder stones or diverticula, or dilation of the upper urinary tract with or without renal insufficiency. Patients were divided in two groups according to the presence of DM. Diabetic groups included 100 patients and non diabetic groups included 200 patients. Patients found to have prostate cancer after prostate biopsies and patients having previous prostate and urethral surgery were excluded from the study. Additionally, patients with bacteriuria or pyuria were excluded likewise.

\section{Measurements}

Detailed medical history and physical examination was performed for all patients. The weight and height of participants were measured and body mass index (BMI) was calculated as weight in kilograms divided by height in meters squared $\left(\mathrm{kg} / \mathrm{m}^{2}\right)$. Blood samples were drawn from fasting patients to determine fasting blood sugar (FBS), HbAlc, total-testosterone (TT), triglycerides (TG) and total cholesterol (C). Prostate volume (PV) was measured according to the prostate ellipsoid formula, multiplying the largest anteroposterior (height, $\mathrm{H}$ ), transverse (width, $\mathrm{W}$ ), and cephalocaudal (length, L) prostate diameters by $0.524(\mathrm{H} \times \mathrm{W} \times \mathrm{L} \times \pi / 6)$ by using transrectal ultrasonography (TRUS). The symptoms of the patients were assesed using international prostate symptom score (IPSS). Post micturion residual volume (PMR) was measured for all patients by ultrasonography. The patients were divided into two groups including diabetic and non diabetic participants.

\section{Statistical analysis}

All statistical analysis was performed by using SPSS ver. 13.0 (SPSS Inc., Chicago, IL, USA). We divided the study population into two groups: the diabetic group and the non-diabetic group. We compared the IPSS, voiding symptom subscore, storage symptom subscore, quality of life (QoL), and prostate related parameters between the two groups. Statistical analysis including Student's t-test and Pearson's correlation coefficient was performed. Student's t-test was used to describe the difference in prostate volume and voiding-related symptom score. Pearson's correlation coefficient was used to test the linearity of the relationships between metabolic components and prostate volume. In all comparisons of values, $\mathrm{p}$-values of less than 0.05 were considered to be statistically significant.

\section{RESULTS}

The mean age of the patients was $68.2 \pm 7.4$ years. The mean age for the two groups were $69.2 \pm 2$ years and $67.8 \pm 7.5$ years, respectively and there was no statistically difference. Baseline characteristics of the patients included in this study are presented in Table 1. BMI in diabetic group was significantly higher. FBS and HbAlc levels were also

Table 1.

found to be statistically differnt $(144.2 \pm 33.5$ and 89.7 \pm 11.9 respectively; $7.3 \pm 1.3$ and $5.6 \pm 0.4$ respectively). Diabetic patients were more likely to report severe LUTS and the symptom score evaluated with IPSS was significantly higher in diabetics group $(19.5 \pm 1.7$ and $18.4 \pm 1.5)$ as post micturional residual volume (104.8 \pm 28.8 and $79.8 \pm 19.8$ respectively). In addition, serum PSA level and PV were significantly higher in the patients with diabetes than in the patients without diabetes. TT levels were significantly lower in diabetic patients than in non diabetic $(2.8 \pm 0.8$ and $3.6 \pm 0.9$ respectively).

Table 2 shows association between the parameteres of diabetic patients including prostate size, T-PSA and TT and the other parameters of all patients. In the analysis a positive link was established between prostate volume and age indicating that older patients are likely to have larger prostate size $(p=0.003)$. Similarly, T-PSA levels correlates with the prostate size $(p=0.00001)$. Another parameter that appears to show a significant link with prostate volume was FBS $(p=0.038)$. A negative correlation was found between TT and T-PSA levels ( $\mathrm{P}=$ 0.006). It was also found that FBS was negatively correlated with TT levels $(p=0.003)$. It was also established that patients with higher post micturion residual volume are likely to have higher T-PSA levels (0.013).

The same comparison between the parameters of non diabetic patients and the parameters in all patients were shown in Table 3. Age and prostate volume significantly correlated, like in diabetic group ( $\mathrm{p}=0.00001)$. BMI and both PV and T-PSA levels were also found to be correlated ( $p=0.002$ and $p=0.006$ respectively). A negative association was established between TT and T- PSA levels ( $p=0.018)$ similarly to the diabetic group. There was also positive correlation between IPSS and T-PSA levels $(p=0.049)$. Conversely from diabetic groups BMI was found to be correlated with PV and T-PSA levels ( $\mathrm{p}=$ 0.002 and $\mathrm{p}=0.006$ respectively).

Baseline charasteristics of men (n: 300) with and without diabetes.

\begin{tabular}{|c|c|c|c|c|}
\hline Characteristic & Total & Patients without DM & Patient with DM & $\mathbf{P}$ \\
\hline No of patients & 300 & 200 & 100 & \\
\hline Age $(y)$ & $68.2 \pm 7.4$ & $67.8 \pm 7.5$ & $69.2 \pm 2$ & 0.11 \\
\hline Weight (kg) & $77.7 \pm 9.1$ & $75.2 \pm 8.9$ & $83.4 \pm 7.6$ & $0.000 *$ \\
\hline Height (cm) & $170.9 \pm 5.3$ & $171.4 \pm 5.3$ & $170.7 \pm 5.6$ & 0.32 \\
\hline $\mathrm{BMI}\left(\mathrm{kg} / \mathrm{m}^{2}\right)$ & $26.2 \pm 2.9$ & $25.2 \pm 2.7$ & $28.1 \pm 2.5$ & $0.000 *$ \\
\hline$\overline{\mathrm{FBS}}(\mathrm{ng} / \mathrm{mL})$ & $106.5 \pm 32.9$ & $89.7 \pm 11.9$ & $144.2 \pm 33.5$ & $0.000^{*}$ \\
\hline HbA1c \% & $6.2 \pm 1.1$ & $5.6 \pm 0.4$ & $7.3 \pm 1.3$ & $0.000^{*}$ \\
\hline $\mathrm{TG}(\mathrm{mg} / \mathrm{dL})$ & $127.4 \pm 44.3$ & $124.3 \pm 46.2$ & $133.7 \pm 39.8$ & 0.08 \\
\hline $\mathrm{C}(\mathrm{mg} / \mathrm{dL})$ & $166.7 \pm 36.1$ & $167.5 \pm 36.7$ & $165.1 \pm 35$ & 0.59 \\
\hline $\mathrm{TT}(\mathrm{ng} / \mathrm{mL})$ & $3.4 \pm 0.9$ & $3.6 \pm 0.9$ & $2.8 \pm 0.8$ & $0.000 *$ \\
\hline $\mathrm{PSA}(\mathrm{ng} / \mathrm{dL})$ & $3.3 \pm 1.3$ & $3.1 \pm 1.4$ & $4.2 \pm 1.7$ & $0.000 *$ \\
\hline PV (ml) & $64.7 \pm 26.4$ & $59 \pm 23.6$ & $85.3 \pm 42.2$ & $0.000^{*}$ \\
\hline IPSS & $18.8 \pm 1.7$ & $18.4 \pm 1.5$ & $19.5 \pm 1.7$ & $0.000 *$ \\
\hline$\overline{\mathrm{PMR}(\mathrm{ml})}$ & $87.7 \pm 25.6$ & $79.8 \pm 19.8$ & $104.8 \pm 28.8$ & 0.000 \\
\hline Uroflow $\left(Q_{\max }\right)$ & $8.8 \pm 1.9$ & $8.8 \pm 1.8$ & $8.9 \pm 2.1$ & 0.73 \\
\hline
\end{tabular}


Table 2

Comparison of prostate size, T-PSA and testosterone of the diabetic patients with other parameters.

\begin{tabular}{|c|c|c|c|c|c|c|}
\hline \multirow[b]{2}{*}{ Parameters } & \multicolumn{2}{|c|}{ Prostate size } & \multicolumn{2}{|c|}{ t-PSA } & \multicolumn{2}{|c|}{ Testosterone } \\
\hline & Correlation ( $r$ ) & $\mathbf{P}$ & Correlation (r) & $\mathbf{P}$ & Correlation (r) & $\mathbf{P}$ \\
\hline$\overline{\text { Age (y) }}$ & $0.291 *$ & 0.003 & 0.104 & 0.303 & -0.181 & 0.072 \\
\hline Weight (kg) & 0.064 & 0.524 & 0.081 & 0.420 & -0.089 & 0.378 \\
\hline Height (cm) & 0.000 & 0.999 & 0.144 & 0.154 & -0.113 & 0.264 \\
\hline $\mathrm{BMI}\left(\mathrm{kg} / \mathrm{m}^{2}\right)$ & 0.087 & 0.387 & -0.024 & 0.815 & 0.013 & 0.895 \\
\hline FBS (ng/mL) & 0.183 & $0.038 *$ & 0.184 & 0.067 & $-0.293 *$ & 0.003 \\
\hline $\mathrm{HbA1c} \%$ & 0.027 & 0.791 & 0.014 & 0.886 & -0.088 & 0.383 \\
\hline $\mathrm{TG}(\mathrm{mg} / \mathrm{dL})$ & 0.066 & 0.513 & 0.084 & 0.406 & -0.140 & 0.165 \\
\hline$\overline{C(m g / d L)}$ & 0.142 & 0.159 & 0.028 & 0.786 & -0.056 & 0.577 \\
\hline$\overline{\mathrm{TT}}(\mathrm{ng} / \mathrm{mL})$ & -0.188 & 0.061 & $-0.273^{*}$ & 0.006 & 1 & \\
\hline PSA (ng/dL) & $0.382 *$ & 0.000 & 1 & & $-0.273^{*}$ & 0.006 \\
\hline $\mathrm{PV}(\mathrm{ml})$ & 1 & & $0.382 *$ & 0.000 & -0.188 & 0.061 \\
\hline IPSS & 0.133 & 0.258 & 0.058 & 0.623 & -0.192 & 0.101 \\
\hline Uroflow $\left(Q_{\max }\right)$ & -0.181 & 0.122 & -0.179 & 0.127 & 0.091 & 0.440 \\
\hline PMR (ml) & 0.316 & 0.005 & $0.279 *$ & 0.013 & -0.140 & 0.222 \\
\hline \multicolumn{7}{|c|}{$\begin{array}{l}\text { * statistically significant; - negative correlation. } \\
\text { BMI: body mass index, FBS: fasting blood glucose, TG: triglycerides, C: cholesterol; TT: total testosterone, } \\
\text { PSA: prostate specific antigen, PV: prostate volume, IPSS: international prostate symptom score, } \\
\text { PMR: Post micturion residual volume. }\end{array}$} \\
\hline
\end{tabular}

Table 3.

Comparison of prostate size, T-PSA and testosterone of non diabetic patients with other parameters.

\begin{tabular}{|c|c|c|c|c|c|c|}
\hline \multirow[b]{2}{*}{ Parameters } & \multicolumn{2}{|c|}{ Prostate size } & \multicolumn{2}{|c|}{ t-PSA } & \multicolumn{2}{|c|}{ Testosterone } \\
\hline & Correlation (r) & $\mathbf{P}$ & Correlation (r) & $\mathbf{P}$ & Correlation ( $r$ ) & $\mathbf{P}$ \\
\hline Age $(y)$ & $0.255^{*}$ & 0.000 & 0.060 & 0.396 & $-0.215^{*}$ & 0.002 \\
\hline Weight (kg) & $0.233^{*}$ & 0.001 & $0.157^{*}$ & 0.026 & 0.009 & 0.902 \\
\hline Height (cm) & 0.078 & 0.270 & -0.041 & 0.569 & -0.037 & 0.607 \\
\hline BMI (kg/m2) & $0.220 *$ & 0.002 & 0.192* & 0.006 & 0.013 & 0.851 \\
\hline FBS $\quad(n g / m L)$ & 0.045 & 0.529 & 0.103 & 0.145 & -0.051 & 0.473 \\
\hline $\mathrm{HbA1c} \%$ & 0.109 & 0.124 & 0.039 & 0.582 & -0.004 & 0.955 \\
\hline$\overline{T G} \quad(\mathrm{mg} / \mathrm{dL})$ & 0.077 & 0.281 & 0.076 & 0.287 & -0.069 & 0.330 \\
\hline $\bar{C}(\mathrm{mg} / \mathrm{dL})$ & -0.001 & 0.992 & -0.005 & 0.942 & -0.052 & 0.461 \\
\hline$\overline{\Pi T}(\mathrm{ng} / \mathrm{mL})$ & -0.042 & 0.551 & $-0.166 *$ & 0.018 & 1 & \\
\hline T-PSA (ng/dL) & $0.273^{*}$ & 0.000 & 1 & & $-0.166^{*}$ & 0.018 \\
\hline PV (ml) & & $0.273^{*}$ & 0.000 & -0.042 & 0.551 & \\
\hline IPSS & -0.052 & 0.510 & 0.155* & 0.049 & 0,030 & 0.706 \\
\hline Uroflow(Qmax) & $-0.176 *$ & 0.026 & -0.017 & 0.832 & -0.059 & 0.459 \\
\hline PMR (ml) & -0.054 & 0.496 & 0.015 & 0.853 & -0.043 & 0.585 \\
\hline \multicolumn{7}{|c|}{$\begin{array}{l}\text { * statistically significant; - negative correlation. } \\
\text { BMI: body mass index, FBS: fasting blood glucose, TG: triglycerides, C: cholesterol; TT: total testosterone, } \\
\text { PSA: prostate specific antigen, PV: prostate volume, IPSS: international prostate symptom score, } \\
\text { PMR: Post micturion residual volume. }\end{array}$} \\
\hline
\end{tabular}

static and dynamic components. In this study we observed a significant correlation between prostate volume and diabetes. There may be several mechanism attributed to this condition particularly including hyperinsulinemia and insülin growth factor (IGF). It has been known for decades that prostatic tissue has IGF receptors which exist in both stromal and epithelial cells $(23,24)$. It has been demonstrated in experimental models that prostate atrophy induced by androgen deprivation as well as with the effect of antiandrogens and of 5 alfa reductase inhibitors is achieved through local growth factors $(25,26)$. The activity of IGF is likely to be managed by the adrogens and in the absence of androgens insuline like growth factor binding protein (IGFBP) levels reduces like IGF-1 receptors and IGF-1 mRNA (27). Some studies established some evidences that insulin resistance is an important factor for enhancement of prostate gland. The decrease in the level of insulin was supposed to be correlated with the reduction of PV $(28,29)$.

We also observed significant correlation between PV and FBS. Won Tae Kim et al. found positive correlation between PV and FBS in non diabetic benign prostatic hiperplasia patients with normal TT levels (30). This study indicate that other unknown factors affecting prostate growth through other mechanism than testosterone such as obesity or abnormal glucose homeostasis. In another study including 422 men Parsons et al reported obesity, elevated fasting glucose and diabetes as risk factors for larger prostate size (31). A study giving similar result by Ozden et al was reported demonstrating significantly higher annual rates of increase in the volume of the transizional area in diabetics compared to the patients with low levels of serum glucose (12). The pathogenesis of this connection may result from insulin resistance and high insulin levels in the blood. Vikram et al. reported enhancement in the proliferation of prostatic epitels in insulin resistans rat model (32). In another study by the same authors hipoinsulinemia was found to be correlated with decrease in the prostate volume (28). Similarly, Hammareston and et al. described a relationship between plasma insulin levels

\section{Discussion}

In this study clinical parameters of BPH in diabetic and non diabetic patients undergoing surgery were compared. Since the etiology of BPH is still unclear and probably depends on a complex mechanism, there is an enhanching attention of researchers about this topic. The connection of diabetes and $\mathrm{BPH}$ has been known for years being firstly mentioned by Bourke and Griffin who suggest an association between diabetes and BPH etiology based on the higher prevalance of diabetes mellitus among patients in need of surgery (22).

$\mathrm{DM}$ seems to play role in pathogenesis of BPH via both and BPH showing that patients with higher levels of plasma fasting insulin had a significantly larger prostate volume and higher annual BPH growth (13). In another study by Sarma et al. investigating the association between DM and BPH parameters in community dwelling black and white men it was found that DM was more related to dynamic components of BPH (24). On the contrary, we found that DM was related to both static and dynamic components of BPH/LUTS. We observed that prostate volume was higher in diabetic counterparts as well as high IPSS and post micturional residual volume. 
We also observed that DM affects the functional components of low urinary tract system. The post micturition residual volume and the symptom score evaluated with IPSS were quite higher in diabetic patients suggesting detrusor impairment (33) which is very frequent in diabetic patients. The distinction between LUTS secondary to DM and LUTS secondary to BPH is difficult to distinguish. Altough both irritative and obstructive symptoms are prevalant in diabetic patients the bothersome of irritative symptoms are more common in patients with $39 \%-61 \%$ of them having some degree of frequency and urgency $(34,35)$. There are many mechanisms proposed to associate the development of low urinary tract symptoms in diabetic patients. Firstly, hyperinsulinemia associated with increased sympathetic activity via enhanced glucose metabolism in ventromedial hypothalamic neurons (36) may contribute to an increase in the activation of the alfa adrenergic pathway with contraction of smooth muscle of the urinary tract contributing to the development of LUTS. This concept was studied in the rat model by McVary et al. who observed an association between autonomic neural input to the prostate and the prostatic growth rate whereas the absence of this input resulted in regression of the gland volume (37).

In this study, we observed that in diabetic patients the TT levels are lower than non diabetic counterparts. Altough BPH is known as an androgen dependent disease this finding may indicate that development of disease is not only depend on TT but on many various hormonal and local growth factor interactions. A study by Rohrmann et al. (38) including 260 individuals from NHANES III reported that elevated estrogen levels and molar estradiol/testosterone ratios as well as lower androstanediol glucuronide (a metabolite of dihydroxytestosterone [DHT]) levels were associated with greater LUTS risk. A direct correlation was found by Schatzl et al. (39) between elevated estradiol levels and prostatic volume determined by TRUS. There are number of studies with contradictory findings to indicate that the regulation and impact of sex hormones on prostatic growth and $\mathrm{BPH}$ is quite complex (40).

\section{Conclusions}

We have presented an association between DM and increased prostate volume indicating that $\mathrm{DM}$ is an important factor for static component of BPH/LUTS. Furthermore we demonstrated association between dynamic components of BPH and diabetes. Peak urinary flow rate was lower and post micturonal residual volume was higher in diabetic group indicating diabetes is associated with not only static components but also with dynamic components of BPH/LUTS. Further evaluations of the association between diabetes and BPH with larger populations are warranted.

\section{REFERENCES}

1. Berry SJ, Coffey DS, Walsh PC, Ewing LL. The development of human benign prostatic hyperplasia with age. J Urol. 1984; 132:474-9.

2. Lee C, Kozlowski JM, Grayhack JT. Etiology of benign prostatic hyperplasia. Urol Clin North Am. 1995; 22:237-46.
3. Donnell RF. Benign prostate hyperplasia: a review of the year's progress from bench to clinic. Curr Opin Urol. 2011; 21:22-6.

4. Partin AW, Oesterling JE, Epstein JI, et al. Influence of age and endocrine factors on the volume of benign prostatic hyperplasia. $J$ Urol. 1991; 145:405-409.

5. Hammarsten J, Hogstedt B, Holthuis N, Mellstrom D. Components of the metabolic syndrome risk factors for the development of benign prostatic hyperplasia.Prostate Cancer Prostatic Dis. 1998; 1:157-162.

6. Michel MC, Mehlburger L, Schumacher H, et al. Effect of diabetes on lower urinary tract symptoms in patients with benign prostatic hyperplasia. J Urol. 2000; 163:1725-1729.

7. Boon TA, Van Venrooij GE, Eckhardt MD. Effect of diabetes mellitus on lower urinary tract symptoms and dysfunction inpatients with benign prostatic hyperplasia. Curr Urol Rep. 2001; 2:297-301.

8. Mongiu AK, McVary KT. Lower urinary tract symptoms, benign prostatic hyperplasia and obesity Curr Urol Rep. 2009; 10:247-53.

9. Hammarsten J, Damber JE, Karlsson M, et al. Insulin and free oestradiol are independent risk factors for benign prostatic hyperplasia.prostate Cancer Prostatic Dis. 2009; 12:160-5.

10. Nandeesha H, Koner BC, Dorairajan LN, Sen SK. Hyperinsulinemia and dyslipidemia in non-diabetic benign prostatic hyperplasia. Clin Chim Acta. 2006; 370:89 93.

11. McVary K. Lower urinary tract symptoms and sexual dysfunction: epidemiology and pathophysiology. BJU Int. 2006; 2:23-8.

12. Ozden C, Ozdal OL, Urgancioglu G, et al. The correlation between metabolic syndrome and prostatic growth in patients with benign prostatic hyperplasia. Eur Urol. 2007; 51:199-203.

13. Hammarsten J, Högstedt B. Hyperinsulinaemia as a risk factor for developing benign prostatic hyperplasia. Eur Urol. 2001; 39: 151-8.

14. Joseph MA, Harlow SD, Wei JT, et al. Risk factors for lower urinary tract symptoms in a population- based sample of AfricanAmerican men. Am J Epidemiol. 2003; 157:906-14.

15. Laven BA, Orsini N, Andersson SO, et al. Birth weight, abdominal obesity and the risk of lower urinary tract symptoms in a population based study of Swedish men. J Urol. 2008; 179:1891-5.

16. Becker S, Dossus L, Kaaks R. Obesity related hyperinsulinaemia and hyperglycaemia and cancer development. Arch Physiol Biochem 2009; 115:86-96.

17. Kogai MA, Lutov UV, Selyatitskaya VG. Hormonal and biochemical parameters of metabolic syndrome in male patients with body weight excess and obesity. Bull Exp Biol Med. 2008; 146:806-8.

18. Giovannucci E, Rimm EB, Chute CG, et al. Obesity and benign prostatic hyperplasia Am J Epidemiolo 1994; 140:989-1002.

19. Abdollah F, Briganti A, Suardi N, et al. Metabolic syndrome and benign prostatic hyperplasia: evidence of a potential relationship, hypothesized etiology, and prevention Korean J Urol. 2011; 52:507516.

20. Ansari MA, Begum D, Islam F. Serum sex steroids, gonadotrophins and sex hormone-binding globulin in prostatic hyperplasia. Ann Saudi Med. 2008; 28:174-8.

21. Roberts RO, Jacobson DJ, Rhodes T, et al. Serum sex hormones and measures of benign prostatic hyperplasia. Prostate. 2004; 61:124-31

22. Bourke JB, Griffin JP. Hypertension, diabetes mellitus, and blood groups in benign prostatic hypertrophy Br J Urol. 1966; 38:18-23. 
23. Safarinejad MR. Prevalence of benign prostatic hyperplasia in a population-based study in Iranian men 40 years old or older Int Urol Nephrol. 2008; 40:921-931.

24. Sarma AV, Burke JP, Jacobson DJ, et al. Associations between diabetes and clinical markers of benign prostatic hyperplasia among community-dwelling black and white men. Diabetes Care. 2008; 31:476-482.

25. Peehl DM, Cohen P, Rosenfeld RG. The insulin-like growth factor system in the prostate World J Urol. 1995; 13:306-311.

26. Zhang J, Hess MW, Thurnher M, et al. Human prostatic smooth muscle cells in culture: estradiol enhances expression of smooth muscle cell-specific markers Prostate. 1997; 30:117-129.

27. Gregory CW, Kim D, Ye P, et al. Androgen receptor up-regulates insulin-like growth factor binding protein-5 (IGFBP-5) expression in a human prostate cancer xenograft Endocrinology. 1999; 140:2372-2381.

28. Vikram A, Tripathi DN, Ramarao P, Jena GB. Intervention of $D$-glucose ameliorates the toxicity of streptozotocin in accessory sex organs of rat. Toxicol Appl Pharmacol. 2008; 226:84-93.

29. Ikeda K, Wada Y, Foster HE Jr, et al. Experimental diabetesinduced regression of the rat prostate is associated with an increased expression of transforming growth factor-beta. J Urol. 2000; 164:180-5.

30. Kim WT, Yun SJ, Choi YD, et al. J Korean Med Sci. 2011; 26:1214-8

31. Parsons JK, Carter HB, Partin AW, et al. Metabolic factors associated with benign prostatic hyperplasia. J Clin Endocrinol Metab. 2006; 91:2562-8.
32. Vikram A, Jena GB, Ramarao P. Increased cell proliferation and contractility of prostate in insulin resistant rats: linking hyperinsulinemia with benign prostate hyperplasia. Prostate. 2010; 70:79-89.

33. Michel MC, Mehlburger L, Schumacher H, et al. Effect of diabetes on lower urinary tract symptoms in patients with benign prostatic hyperplasia. J Urol 2000; 163:1725-1729.

34. Kaplan SA, Te AE, Blaivas JG. Urodynamic findings in patients with diabetic cystopathy J Urol. 1995; 153:342-344.

35. Brown JS, Wessells H, Chancellor MB. Urologic complications of diabetes Diabetes Care. 2005; 28:177-185.

36. Landsberg L. Diet, obesity and hypertension: an hypothesis involving insulin, the sympathetic nervous system, and adaptive thermogenesis. QJ Med. 1986; 61:1081-90.

37. McVary KT, Razzaq A, Lee C, et al. Growth of the rat prostate gland is facilitated by the autonomic nervous system. Biol Reprod. 1994; 51:99-107.

38. Rohrmann S, Nelson WG, Rifai N, et al. Serum sex steroid hormones and lower urinary tract symptoms in Third National Health and Nutrition Examination Survey (NHANES III). Urology. 2007; 69:708-13.

39. Schatzl G, Brossner C, Schmid S, et al. Endocrine status in elderly men with lower urinary tract symptoms: correlation of age, hormonal status, and lower urinary tract function, The Prostate Study Group of the Austrian Society of Urology. Urology. 2000; 55:397402.

40. Gann PH, Hennekens $\mathrm{CH}$, Longcope C, et al. A prospective study of plasma hormone levels, nonhormonal factors, and development of benign prostatic hyperplasia. Prostate. 1995; 26:40-9.

\section{Correspondence}

Levent Ozcan, MD (Corresponding Author)

drleventozcan@yahoo.com

Derince Training and Research Hospital, Department of Urology,

Kocaeli, Turkey

Huseyin Besiroglu, MD

Emre Can Polat, MD

Alper Otunctemur, MD

Emin Ozbek, MD

Okmeydani Training and Research Hospital, Department of Urology, Istanbul, Turkey

Murat Dursun, MD

Bahcelievler State Hospital, Department of Urology, Istanbul, Turkey 